\title{
Envenenamento experimental por Bothropoides jararaca e Bothrops jararacussu em ovinos: aspectos clínico- patológicos e laboratoriais ${ }^{1}$
}

\author{
Ana Paula Aragão², Carlos H. Tokarnia ${ }^{3}$, Flávio A.S. Graça ${ }^{4}$, Ticiana N. \\ França ${ }^{5}$, Cleide D. Coelho ${ }^{2}$, Saulo A. Caldas ${ }^{2}$ e Paulo V. Peixoto ${ }^{3}$
}

\begin{abstract}
Aragão A.P., Tokarnia C.H., Graça F.A.S., França T.N., Coelho C.D., Caldas S.A. \& Peixoto P.V. 2010. [Experimental poisoning by Bothropoides jararaca and Bothrops jararacussu in sheep: Clinic-pathological and laboratory aspects.] Envenenamento experimental por Bothropoides jararaca e Bothrops jararacussu em ovinos: aspectos clínico-patológicos e laboratoriais. Pesquisa Veterinária Brasileira 30(9):717728. Projeto Sanidade Animal Embrapa/UFRRJ, Seropédica, RJ 23890-000, Brazil. Email: paulaaragao.vet@gmail.com

The purpose of this study was to establish the clinic-pathological and laboratory changes in sheep inoculated with Bothropoides jararaca and Bothrops jararacussu venom to provide subsidies for the differential diagnosis of snake bites. The liofilized venoms were diluted in $1 \mathrm{ml}$ saline and administrated subcutaneously to four sheep. Three of the animals died, and the one that received $0.5 \mathrm{mg} / \mathrm{kg}$ ( $B$. jararaca venom) recovered. First symptoms were observed from 7 minutes to 1 hour after inoculation, and the clinical course varied from 7 hours and 9 minutes to 21 hours and 59 minutes. The symptoms, independent of the dosage, were swelling of the inoculation site, increased bleeding time and capillary filling, tachycardia, dyspnea, pale mucous membranes and diminished reaction to external stimuli. Laboratory tests revealed pronounced normocytic and normochromic anemia, trombocytopenia, slight reduction of fibrogen and total plasmatic protein, in two animals diminished hematocrit, besides pronounced increase of creatinaquinase and lactic dehydrogenase. At necropsy, the main findings at the inoculation site and adjacent tissues were extensive hemorrhages in the sheep inoculated with jararaca venom, and predominantly edema in the two animals inoculated with jararacussu venom. In two sheep which received jararacussu venom, acute pulmonary edema was observed. Hemorrhage and edema as the main histopathological changes, besides necrosis of muscle fibers and vessels at the inoculation site and adjacent tissue was observed. The renal tubular necrosis was attributed to shock. The volume increase at the inoculation site and surroundings was mainly due to hemorrhage (B. jararaca) or edema (B. jararacussu).
\end{abstract}

INDEX TERMS: Snake bite, Bothrops jararaca, Bothropoides jararaca, Bothrops jararacussu, sheep.

\footnotetext{
${ }^{1}$ Recebido em 16 de março de 2010.

Aceito para publicação e 10 de abril de 2010.

2 Curso de Pós-Graduação em Ciências Veterinárias, Universidade Federal Rural do Rio de Janeiro (UFRRJ), Seropédica, RJ 23890-000,

Brasil. *Autor para correspondência: paulaaragao.vet@gmail.com

${ }^{3}$ Departamento de Nutrição Animal e Pastagem, Instituto de Zootecnia, UFRRJ, Seropédica, RJ.

4 Departamento de Clínica de Animais de Produção, Universidade Castelo Branco, Av. Brasil 9727, Rio de Janeiro, RJ 21021-020, Brasil.

${ }^{5}$ Departamento de Epidemiologia e Saúde Pública, Instituto de Veterinária, UFRRJ, Seropédica, RJ.
}

RESUMO.- Esse estudo teve como objetivo determinar as alterações clínico-patológicas e laboratoriais em ovinos inoculados com a peçonha de Bothropoides jararaca e Bothrops jararacussu, no intuito de fornecer subsídios que possam facilitar o estabelecimento do diagnóstico e do diagnóstico diferencial dessa condição. Os venenos liofilizados foram diluídos em $1 \mathrm{ml}$ de solução fisiológica e administrados a quatro ovinos por via subcutânea. Três ovinos foram a óbito e um que recebeu a dose de $0,5 \mathrm{mg} / \mathrm{kg}$ (B. jararaca), recuperou-se. Os sinais clínicos tiveram iní- 
cio entre 7 minutos e 1 hora. O período de evolução variou de 7 horas 9 minutos a 21 horas 59 minutos. O quadro clínico, independentemente das doses, caracterizou-se por aumento de volume no local da inoculação, tempo de sangramento e de preenchimento capilar aumentados, taquicardia, dispnéia, mucosas hipocoradas e apatia. Os exames laboratoriais revelaram acentuada anemia normocítica normocrômica, trombocitopenia, acentuada redução de fibrinogênio e proteínas plasmáticas totais, hematócrito diminuído em dois animais, além de acentuado aumento de creatinaquinase e desidrogenase lática em todos os animais. À necropsia, os principais achados no local da inoculação e tecidos adjacentes eram extensas hemorragias no animal que recebeu o veneno de $B$. jararaca e edema e acentuado edema pulmonar agudo para os dois animais envenenados por $B$. jararacussu. Além de hemorragia e edema a principal alteração histopatológica verificada foi necrose das fibras musculares e de vasos, no local de inoculação e adjacências. A necrose tubular renal foi atribuída ao quadro de choque. Nos ovinos deste estudo, o aumento de volume observado no local de inoculação e adjacências era constituído predominantemente por sangue (B. jararaca) e por edema (B. jararacussu).

TERMOS DE INDEXAÇÃO: Picada de cobra, Bothrops jararaca, Bothropoides jararaca, Bothrops jararacussu, ovinos.

\section{INTRODUÇÃO}

A importância que os acidentes ofídicos têm como causa de morte de bovinos no Brasil foi recentemente avaliada (Tokarnia \& Peixoto 2006). Equívocos e incongruências repetidos na literatura sobre o tema são decorrentes, em parte, da extrapolação de dados relativos ao quadro clínico-patológico verificado em uma espécie animal, para as outras. Ou seja, sinais clínicos e lesões observados em humanos ou em animais de laboratório envenenados por ofídios são simplesmente incorporados às descrições correspondentes ao envenenamento ofídico em bovinos, o que muitas vezes, redunda em erro. Por exemplo, Graça et al. (2008) e Saliba et al. (1983) verificaram que o veneno de Crotalus durissus terrificus ${ }^{6}$ não induz, em bovinos, à mioglobinúria como é comum observar-se em humanos picados por esse tipo serpente no Brasil.

No que se refere a serpentes dos gêneros Bothrops ${ }^{6}$, observou-se que esse tipo de erro também pode ocorrer. O aumento de volume no local da picada de Bothrops alternatus $^{6}$, em bovinos, vem sendo descrito na literatura genericamente como "edema", mas à necropsia verificaram-se no ponto de inoculação, essencialmente, grandes hemorragias e não edema propriamente dito (Caldas et al. 2008). Adicionalmente, encontram-se na literatura, infor-

\footnotetext{
${ }^{6}$ De acordo com Melgarejo (2010), recentemente houve modificações na nomenclatura referentes a algumas serpentes. Por exemplo, Bothrops jararaca passou a denominar-se Bothropoides jararaca, enquanto Bothrops jararacussu manteve a mesma denominação. Já Bothrops alternatus é agora designada por Rhinocerophis alternatus e Crotalus durissus por Caudisona durissa.
}

mações dúbias em relação aos quadros clínico-patológicos induzidos por serpentes do gênero Bothrops e Crotalus; acredita-se que esses erros tenham origem no fato de que as cascavéis norte-americanas produzam e inoculem venenos que tem efeito semelhante ao produzido pelas serpentes do gênero Bothrops ${ }^{6}$ (Tokarnia \& Peixoto 2006).

Dessa forma, esse estudo tem por objetivo principal estabelecer com precisão o quadro clínico-patológico dos envenenamentos por Bothropoides jararaca, a serpente do gênero mais comum e mais freqüentemente implicada em acidentes no Brasil, e por Bothrops jararacussu, em ovinos, como forma de fornecer subsídios que facilitem o diagnóstico correto.

\section{MATERIAL E MÉTODOS}

Os experimentos foram realizados entre abril e junho de 2008 , nas instalações do Setor de Anatomia Patológica, Projeto Sanidade Animal Embrapa/UFRRJ. O estudo experimental foi aprovado pela comissão de ética do Curso de Pós-Graduação em Ciências Veterinárias da UFRRJ. Foram utilizados 4 ovinos, machos, mestiços, clinicamente sadios, com idades de cinco meses a sete anos e pesos entre 20 e $44,5 \mathrm{~kg}$. Os animais foram mantidos em baias individuais de alvenaria de $3,0 \mathrm{~m}$ $x 4,0 m$ ou em piquetes, tratados contra endo e ectoparasitos e adaptados ao local. A dieta era constituída de capim picado ou inteiro e ração concentrada para a manutenção e água à vontade. O processamento do material obtido das necropsias, assim como a confecção de lâminas para o exame histopatológico, foram realizados no laboratório de histopatologia da mesma Instituição. O veneno liofilizado da Bothropoides jararaca e Bothrops jararacussu, proveniente do Instituto Vital Brazil, foi colhido pela extração manual, dessecado a vácuo e mantido congelado a $10^{\circ} \mathrm{C}$ negativos, pesado em balança eletrônica de precisão e reconstituído em $1 \mathrm{ml}$ de soro fisiológico no momento de sua utilização.

Inicialmente foram utilizados dois animais, Ovino 5751 ( $B$. jararaca, dose 1,0mg/kg) e Ovino 5752 (B. jararacussu, dose $1,6 \mathrm{mg} / \mathrm{kg}$ ), com a inoculação por via subcutânea na face esquerda, região do músculo masseter, previamente tricotomizada. O experimento subsequente foi realizado, com os Ovinos 5753 (B. jararaca, dose 0,5mg/kg) e 5754 (B. jararacussu, dose $0,8 \mathrm{mg} / \mathrm{kg}$ ), a inoculação dos venenos foi por via subcutânea no membro posterior direito (MPD), na região do músculo semi-membranoso. O delineamento experimental teve como objetivo caracterizar os achados clínico-patológicos e laboratoriais do envenenamento por essas duas serpentes em ovinos, com o menor número possível de animais.

Os animais que foram submetidos à inoculação no membro posterior direito receberam, via cateter epidural, morfina na dose de $0,1 \mathrm{mg} / \mathrm{kg}$ diluída em $1 \mathrm{ml}$ de solução fisiológica cada 12 horas por um período máximo de quatro dias, para a produção de alívio da dor (Muir \& Hubbell 1995).

Os ovinos foram acompanhados clinicamente, a cada duas horas, até o óbito ou até a completa recuperação. Foram feitas colheitas de sangue (hemograma completo, determinações de fibrinogênio e proteínas plasmáticas totais) de cada animal. As amostras de sangue destinadas à bioquímica sérica (uréia, creatinina, creatinaquinase e dehidrogenase láctica) foram colhidas em frascos que permitiram a formação e retração do coágulo, com exceção daquelas destinadas ao coagulograma 
(tempo de ativação da protrombina, tempo de tromboplastina parcial ativada, as quais foram colocadas em frascos com citrato de sódio. Já as amostras destinadas à realização de hemograma foram colocadas em frascos com ácido etilenodiaminotetraacético (EDTA) a 10\%. Em todos os animais foram coletadas amostras no tempo zero (T0) e na hora da morte. Para o animal que se recuperou, ainda foram coletadas amostras em 24 e 96 horas após a inoculação (T24 e T96). A avaliação clínica foi realizada a cada duas horas. O tempo de sangramento foi avaliado através da metodologia descrita por Garcia-Navarro \& Pachaly (1994).

As necropsias foram realizadas imediatamente após a morte dos animais, com colheita de encéfalo, medula, hipófise, globo ocular, fragmentos de coração, pulmões, fígado, vesícula biliar, rins, baço, rúmen, retículo, omaso, abomaso, intestinos, bexiga, parótida, tireóide, adrenal, pâncreas, testículos, tecido subcutâneo e músculos do local da inoculação e contralateral e grupos de músculos distantes, colocados em formol a $20 \%$ tamponado com carbonato de sódio. As amostras foram fixadas imediatamente, com exceção dos fragmentos de músculos, os quais eram previamente expostos ao ambiente por duas horas. Os fragmentos sofreram processamento de rotina para histopatologia, cortados a $5 \mu$ e corados pela hematoxilina e eosina (HE).

\section{RESULTADOS}

Os principais dados dos experimentos encontram-se no Quadro 1.

\section{Dose letal}

Em relação a Bothropoides jararaca, 0,5 e 1,0mg/kg determinaram, respectivamente, quadros não-fatal e fatal de envenenamento. Já ambos os Ovinos inoculados com o veneno da Bothrops jararacussu, nas doses de 0,8 e $1,6 \mathrm{mg} / \mathrm{kg}$, morreram.

\section{Quadro clínico geral}

Em todos os animais observaram-se aumento de volume no local da inoculação, alterações no tempo de sangramento e tempo de preenchimento capilar (TPC), independente do local e dose de inoculação.

\section{Bothropoides jararaca}

Ovino 5751 (inoculação face, dose de 1,0mg/kg). Foi observado leve aumento de volume local 7 minutos após a inoculação. Com a evolução do quadro clínico, o animal apresentou grande aumento de volume bilateral na face e na região submandibular (Fig.1), anorexia, dificuldade de ingerir água, apatia, inquietude, sinais de cólica, mucosas extremamente hipocoradas, aumento da freqüência cardíaca, dispnéia e hipotermia. Treze horas e 52 minutos após a inoculação do veneno, o animal liberou sangue vivo nas fezes, mas a urina permaneceu sem alterações. Ao final, o ovino apresentou dificuldade para se levantar e sustentar a cabeça, decúbito esternal e, posteriormente lateral, liberou pequena quantidade de espuma pela boca e morreu.

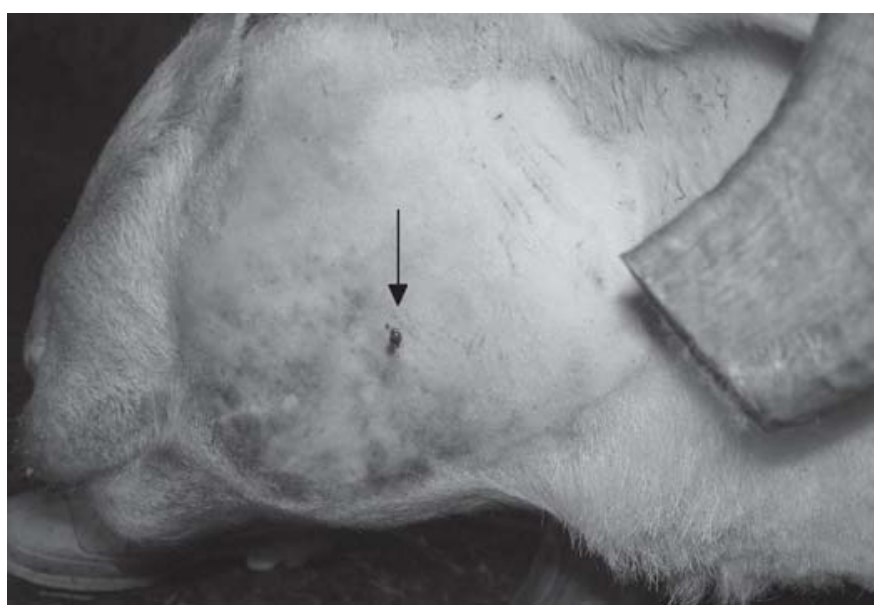

Fig.1. Aumento de volume e avermelhamento sob a pele, com I ponto hemorrágico perceptível (seta) no local da inoculação; 5 horas e 2 minutos após a inoculação. (Ovino 5751, Bothropoides jararaca)

Ovino 5753 (inoculação MPD, dose de $0,5 \mathrm{mg} / \mathrm{kg}$ ). Foi observado leve aumento de volume local 57 minutos após a inoculação. O linfonodo pré-crural direito apresentava-se aumentado e o poplíteo não podia ser palpado devido ao acentuado aumento de volume do membro. $\mathrm{O}$ animal apresentou discreta claudicação e arrastava a pinça ao se locomover. Dezenove horas e 54 minutos após a inoculação foi realizada tricotomia no membro e observado pele arroxeada (hematoma), grande aumento de volume do membro, aumento da temperatura no local e, posteriormente, drenagem de líquido seroso. Com 28 horas após a inoculação do veneno, a bolsa escrotal estava com mo-

Quadro 1. Envenenamento experimental por Bothropoides jararaca e Bothrops jararacussu em ovinos. Principais dados sobre o delineamento experimental e desfecho

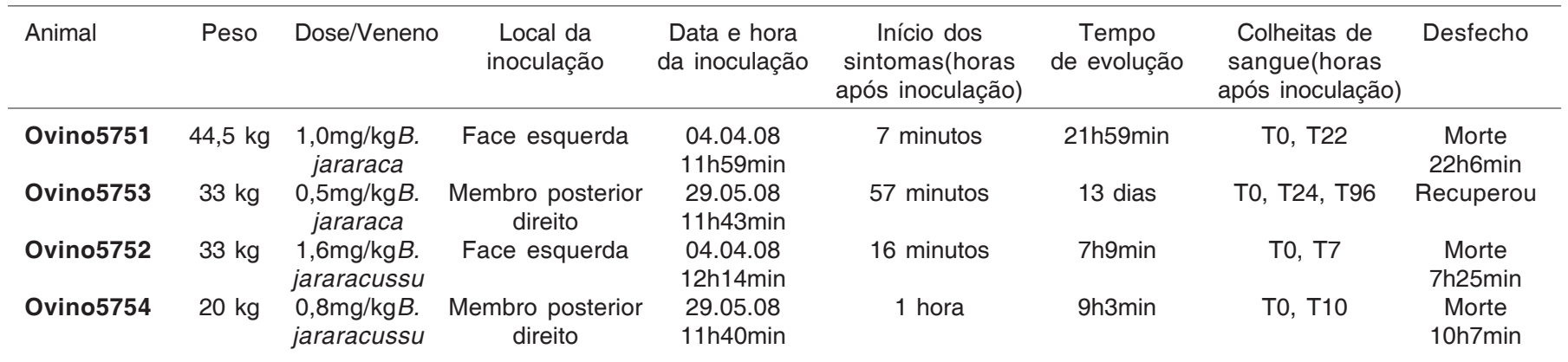




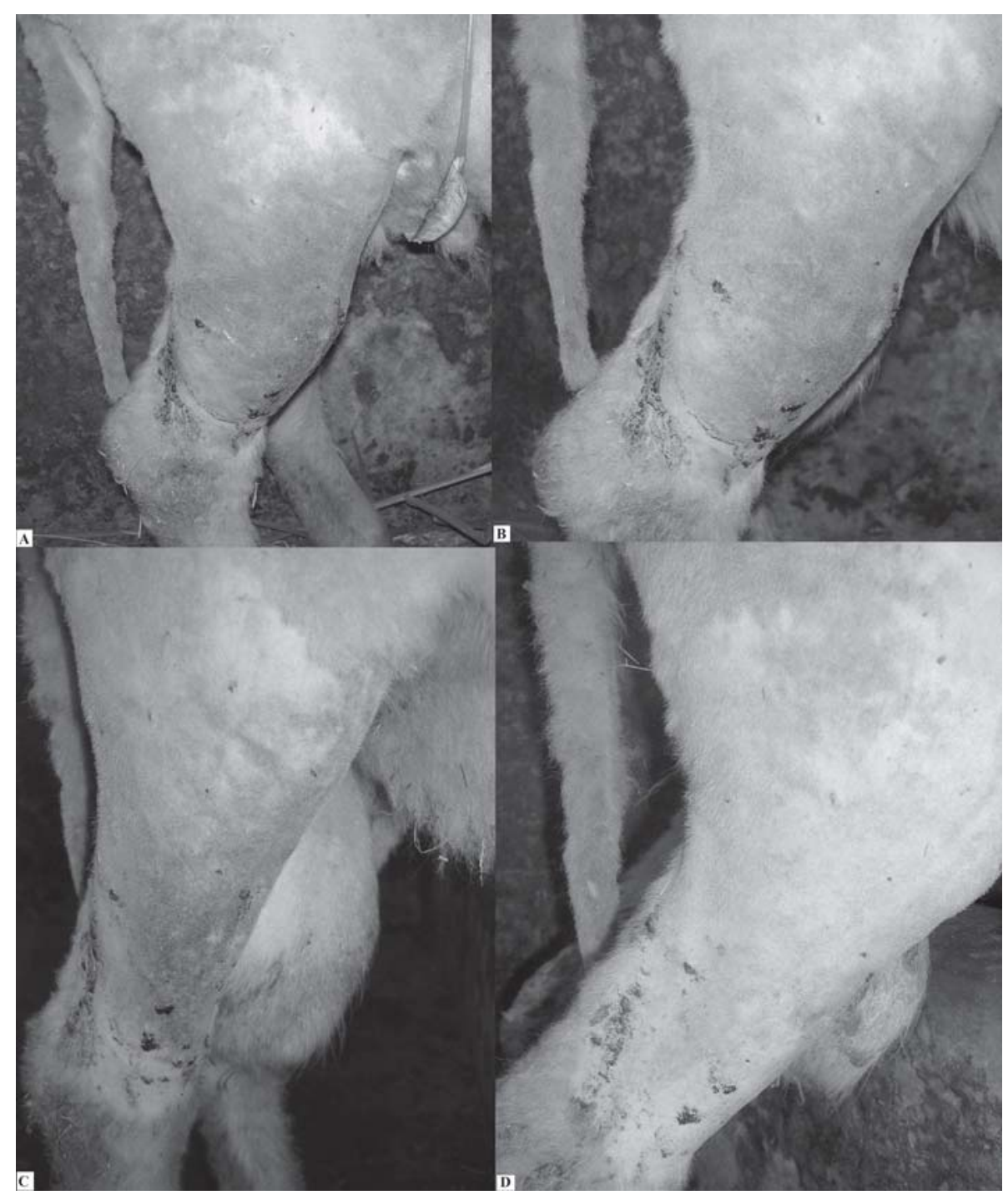

Fig.2. Diferentes fases da regressão das lesões quatro (A), cinco (B), seis (C) e nove (D) dias após a inoculação; esse animal foi considerado totalmente recuperado treze dias após a inoculação. (Ovino 5753, Bothropoides jararaca)

derado aumento de volume. As conjuntivas estavam pálidas. Houve aumento da frequência cardíaca, mas os movimentos respiratórios e ruminais mantiveram-se dentro da normalidade. O animal não demonstrou alterações comportamentais e não deixou de comer ou beber água. Trinta e duas horas e 7 minutos após a inoculação, o membro começou a diminuir de volume e após 13 dias o membro e a bolsa escrotal estavam de tamanho e coloração normais (Fig.2). O animal não apresentou hematomas no local da colheita de sangue.

\section{Bothrops jararacussu}

Ovino 5752 (inoculação face, dose de 1,6mg/kg). 0 ovino apresentou área arroxeada perceptível através da pele, de $3 \mathrm{~cm}$ de diâmetro, com aumento de volume no local da inoculação 16 minutos após o envenenamento e, aos 29 minutos, discreto aumento de volume submandibular. Com 39 minutos após a inoculação do veneno houve mudança de comportamento, o animal tornou-se apático e não se alimentava. O local da inoculação apresentava-se quente, ao contrário da região submandibular que estava mais fria ( 2 horas 26 minutos). Com a evolução, verificouse o aumento de volume até a região do peito e dificuldade respiratória (respiração abdominal). Após 7 horas e 21 minutos, o animal entrou em decúbito esternal, liberou grande quantidade de espuma pelas narinas e morreu.

Ovino 5754 (inoculação MPD, dose de 0,8mg/kg). Houve aumento de volume local 1 hora após a inoculação. O animal apresentava dor à palpação e apoiava o membro com dificuldade. Cinco horas e 20 minutos após a inoculação observou-se marcado aumento de volume do membro que se estendeu até abaixo do jarrete (Fig.3) e, em 7 horas e 35 minutos, presença de sangue no termômetro, porém, as fezes mantiveram-se normais. Verificou-se, em 9 horas e 50 minutos após a inoculação, andar cambaleante, freqüência cardíaca 220 batimentos/minuto, acentuada 


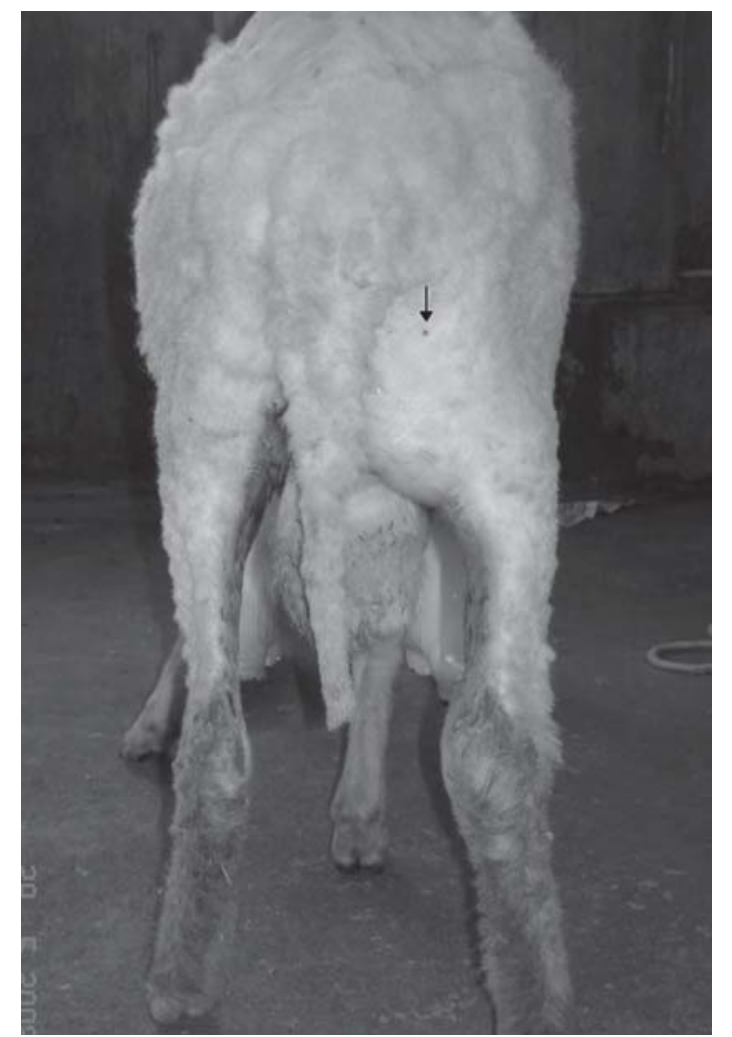

Fig.3. Aumento de volume na altura dos músculos semitendinoso e semi-membranoso. Seta mostra o local da inoculação; 3 horas após a inoculação. (Ovino 5753, Bothropoides jararaca)

dispnéia, estertores pulmonares, decúbito lateral e parada respiratória com liberação de pequena quantidade de espuma pela narina e morte.

\section{Resultados laboratoriais}

Hemograma, proteínas plasmáticas, contagem de plaquetas e fibrinogênio. Na avaliação do eritrograma verificou-se acentuada anemia normocítica normocrômica, entre 22 e 96 horas após a inoculação para os Ovinos 5751 e 5753, respectivamente. Pode-se observar também moderada diminuição no hematócrito e na concentração de hemoglobina nos mesmos animais. Nos Ovinos $5752 \mathrm{e}$ 5754 , houve aumento do hematócrito. Verificaram-se acentuada diminuição de plaquetas e hipofibrinogenemia em todos os animais. As proteínas plasmáticas totais diminuíram acentuadamente em dois animais (Ovinos 5751 e 5753). Os leucogramas apresentaram-se com eosinopenia, linfopenia, neutrofilia relativa e desvio nuclear de neutrófilos à esquerda.

Bioquímica sérica. Todos os animais apresentaram acentuado aumento nos níveis de creatinaquinase (CK) e dehidrogenase lática (DHL). Houve discreto a leve aumento dos valores de uréia, exceto no Ovino 5754, que apresentou discreta diminuição. Os valores de creatinina estavam acentuadamente aumentados nos Ovinos 5752 e 5754, e diminuído no Ovino 5751.
Avaliação da coagulação sanguínea. Para os animais inoculados com o veneno da $B$. jararaca, o tempo de sangramento (TS) em T0 foi de 40 e 30 segundos. Cinco horas após a inoculação esse tempo ficou em 120 e 600 segundos. O tempo de ativação da protrombina (TAP) alcançou níveis elevados, passando de 30 e 32 em T0 para 379 e 360 segundos, e o tempo de tromboplastina parcial ativada (TTPA) passou de 56 e 60 para 172 e 153 segundos.

Nos animais inoculados com o veneno de $B$. jararacussu, o TS no T0 foi de 90 e 30 segundos. Após a inoculação esse tempo ficou em 480 e 180 segundos. O TAP alcançou níveis elevados, passando de 30 e 33 em T0 para 1170 e 374 segundos, e o TTPA passou de 40 e 42 para 900 e 103 segundos.

\section{Bothropoides jararaca \\ Achados de necropsia}

Ovino 5751 (inoculação face, dose de 1,0mg/kg). Antes da necropsia foi realizada tricotomia no lado esquerdo, em toda área que apresentava aumento de volume, da face até a região esternal. O local onde o veneno foi inoculado estava com coloração arroxeada. Havia hemorragia por toda gengiva e no lábio inferior, na face esquerda verificaram-se edema em pálpebra superior, edema e hemorragia em pálpebra inferior e, na face direita, edema de pálpebra superior. Ao corte evidenciou-se muito sangue em tecido subcutâneo (parte coagulado, parte fluido) e algumas áreas com deposição de substância gelatinosa, de coloração citrina (edema), em meio ao tecido muscular adjacente. Notou-se hemorragia no interior do músculo cervical e edema hemorrágico no músculo masseter contralateral que se estendia até a região pré-escapular (Fig.4).

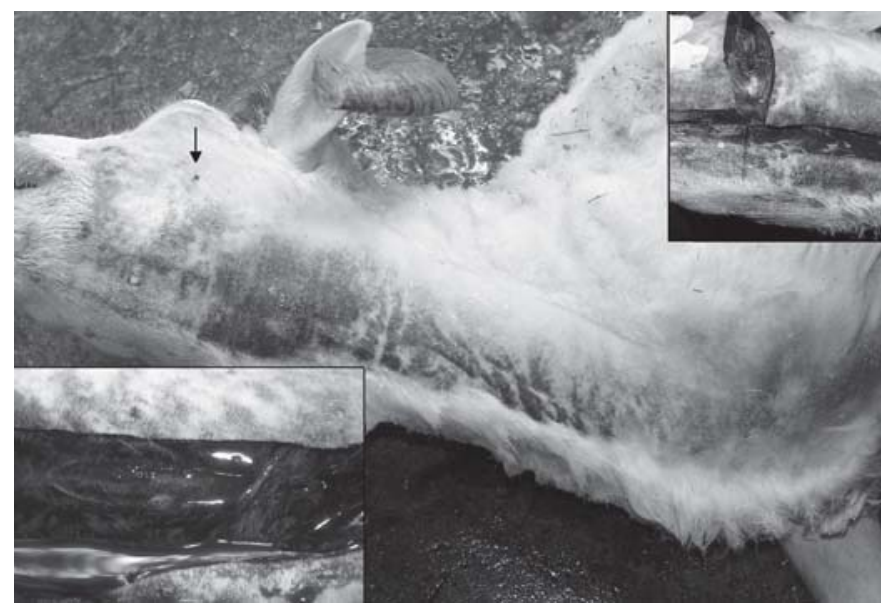

Fig.4. Acentuado avermelhamento escuro com aumento de volume, perceptíveis através da pele, que se estende desde a comissura labial até a região esternal (imediatamente antes da necropsia). A seta aponta o local da inoculação. Nos detalhes, (A) presença de sangue em tecido subcutâneo e intermuscular na região submandibular adjacente ao local da inoculação e na área cervical ventral. (B) Predomínio de "edema hemorrágico". (Ovino 5751, Bothropoides jararaca) 
Adicionalmente observaram-se sangue e edema na entrada da cavidade torácica, que se estendia até a região esternal, presença de pequena quantidade de líquido de coloração avermelhada na cavidade torácica direita e algumas sufusões subpleurais nos lobos craniais do pulmão, além de pequena quantidade de líquido no saco pericárdico, hemorragias subendocárdicas na altura do músculo papilar e na válvula mitral, na parede livre e do septo. Verificaram-se petéquias a equimoses na serosa e mucosa do omaso e mucosa do abomaso. O linfonodo justaposto ao omaso apresentava-se hemorrágico. Notaram-se áreas tingidas de vermelho na mucosa do jejuno, muco e sangue em cólon espiral e sangue não coagulado na porção final do intestino. Não foram observadas alterações em rins ou bexiga.

\section{Bothrops jararacussu}

Ovino 5752 (inoculação face, dose de 1,6mg/kg). No entorno do local da inoculação havia área vermelhoarroxeada, com limites pouco precisos, de aproximadamente $2 \mathrm{~cm}$ de diâmetro; ao corte verificou-se edema levemente tingido de vermelho até a profundidade de $0,5 \mathrm{~cm}$ (fáscia do músculo masseter); por sob a pele, esse edema se estendia por toda região submandibular até a região esternal (Fig.5). Havia acentuada quantidade de conteúdo espumoso de coloração esbranquiçada na traquéia e brônquios (Fig.6) e sufusões e edema (substância gelatinosa) no subendocárdio, bem como áreas de hemorragias no abomaso, úlcera linear no pilar do rúmen, conteúdo líquido avermelhado no duodeno e petéquias na serosa do duodeno, jejuno e cólon espiral. Verificaram-se ainda leve congestão hepática e dos vasos do cérebro e moderada congestão renal; a junção córtico-medular estava acentuadamente congesta.

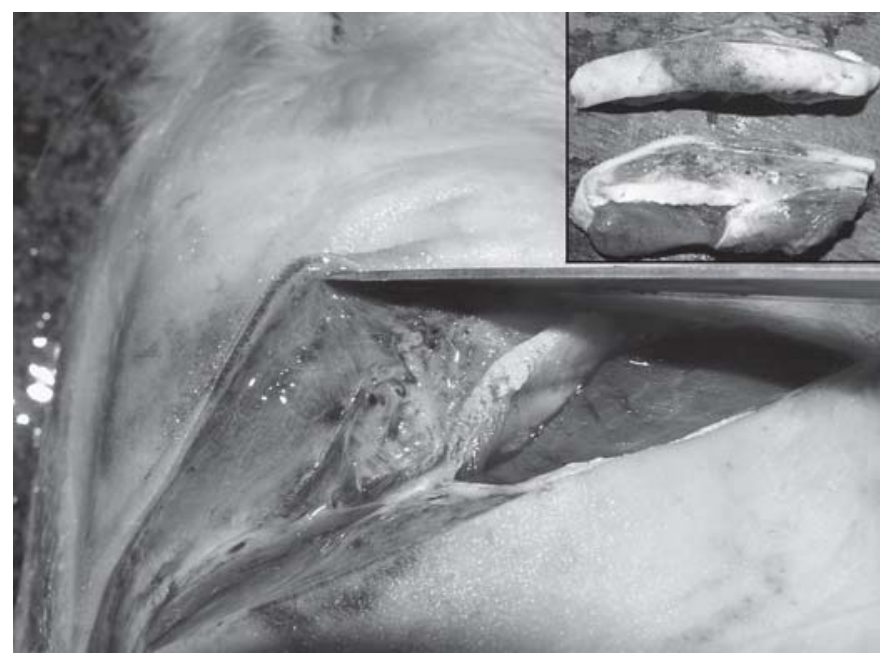

Fig.5. Pele com discreta hemorragia no local da inoculação e moderado edema do tecido celular subcutâneo subjacente. No detalhe, fragmentos de pele e tecido subjacentes ao local da inoculação. No fragmento superior nota-se pele de cor vermelho-escura e, no segundo, edema subcutâneo. (Ovino 5752, Bothrops jararacussu)

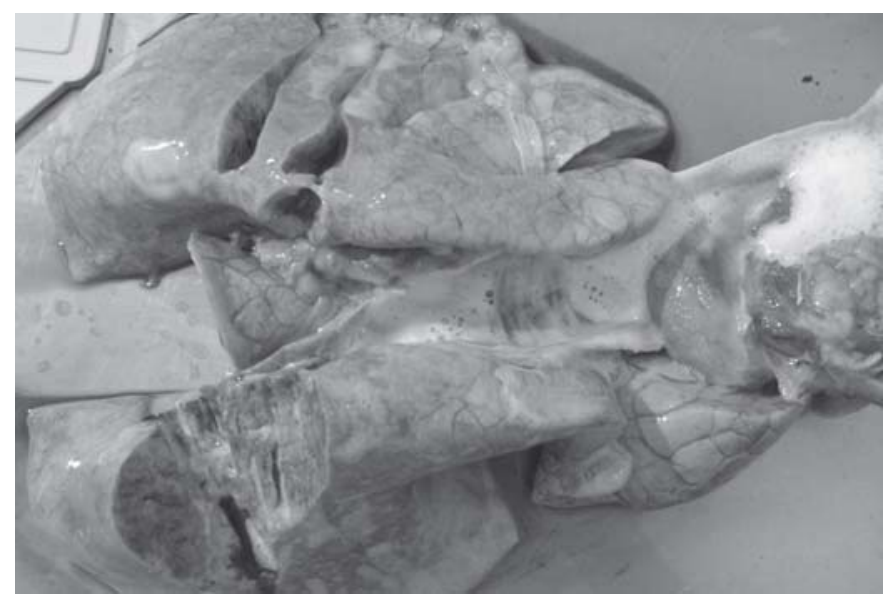

Fig.6. Grande quantidade de espuma esbranquiçada (edema) dentro da traquéia, brônquios e parênquima pulmonar. (Ovino 5752, Bothrops jararacussu)

Ovino 5754 (inoculação MPD, dose de $0,8 \mathrm{mg} / \mathbf{k g}$ ). Acentuado aumento de volume que se estendia, por todo o membro, desde o limite da cavidade pélvica até o casco, caracterizado por edema subcutâneo, intramuscular e intermuscular. Ao corte os músculos drenavam líquido seroso. Observou-se edema no linfonodo poplíteo, mesentéri$\mathrm{co}$, em um linfonodo ruminal e ao redor do cordão espermático; o testículo direito apresentava-se hemorrágico. Verificou-se presença de espuma nas narinas, na região da glote e na traquéia, pulmão armado e pesado, com leve congestão difusa e grande quantidade de espuma em árvore brônquica, além de leve hidrotórax direito e hidropericárdio. Os rins estavam congestos e o rim direito apresentava superfície de corte brilhante e o córtex da adrenal estava hemorrágico.

\section{Achados histopatológicos}

Para o animal que recebeu o veneno de Bothropoides jararaca (Ovino 5751) havia, no local da inoculação, necrose na porção superficial da derme, delimitada por com linha de demarcação inflamatória. Na derme profunda e tecido celular subcutâneo foram observados edema, hemorragia e necrose e, na musculatura subjacente, havia hemorragia com leve edema e necrose coagulativa, caracterizada por marcada eosinofilia citoplasmática (hialinização de fibras), picnose nuclear, com ruptura de fibras musculares associada à infiltração por neutrófilos entre e sobre as fibras necróticas. Verificaram-se também alterações degenerativas e necróticas na parede de alguns vasos, representadas por tumefação e vacuolização endotelial e da média, deposição de substância amorfa e eosinofílica na parede de vasos, picnose nuclear e formação de trombos, além de necrose hialina com hemorragia intramural em arteríolas (Fig.7 e 8). Na região contralateral à inoculação havia acentuada hemorragia em tecido subcutâneo e em musculatura adjacente com necrose hialina de fibras musculares, menos evidente quando comparada à região da inoculação. Já na derme profunda, havia necrose hialina de vênulas, tumefação endotelial e migração de neu- 


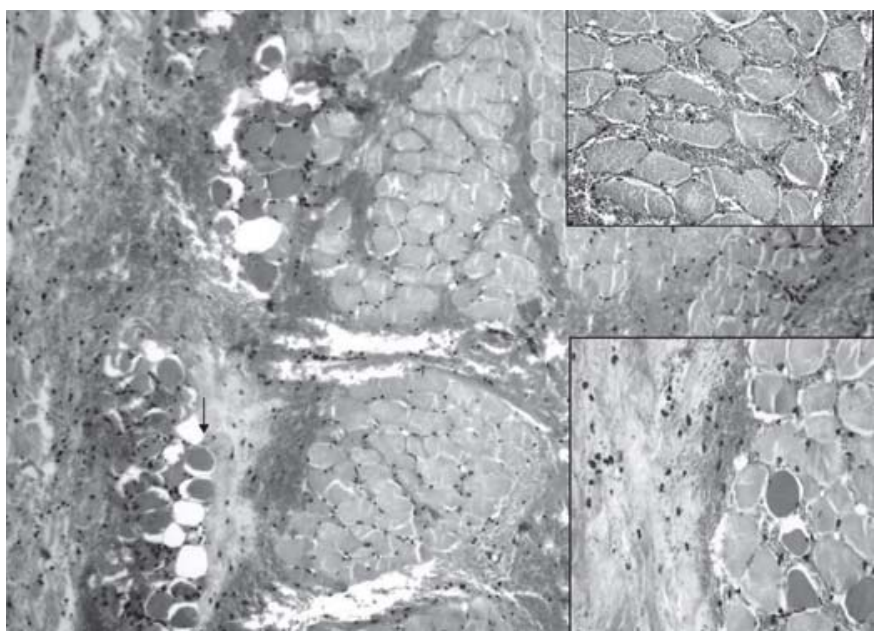

Fig.7. Musculatura adjacente ao local da inoculação. Observase hemorragia por entre grupos de fibras musculares. $\mathrm{Na}$ seta, fibras musculares necróticas ("hialinizadas") associada à infiltração inflamatória incipiente. HE, obj.6.3x. Nos detalhes, $(\mathbf{A})$ hemorragia intersticial sem alterações morfológicas de fibras. HE, obj.25x. (B) "edema hemorrágico" com presença de fibrina, algumas células inflamatórias e "hialinização" de fibras musculares. HE, obj.16x. (Ovino 5751, Bothropoides jararaca)

trófilos pela parede dos vasos. Hemorragia entre as fibras colágenas em subcutâneo e derrame serofibrinoso também foram evidenciados.

As principais alterações encontradas nos rins foram leve picnose incipiente, por vezes, com tumefação citoplasmática ou, menos frequentemente, com aumento da eosinofilia em túbulos uriníferos. Em algumas áreas havia evolução para lise das células tubulares, aumento do filtrado glomerular, túbulos levemente dilatados, além de mineralização de alguns túbulos da medular. No fígado notou-se leve a

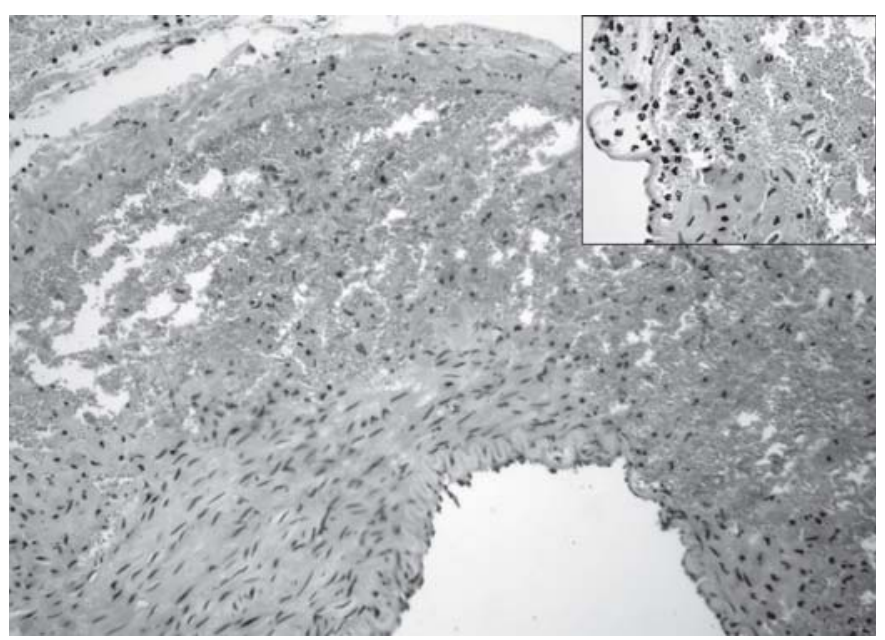

Fig.8. Artéria no tecido celular subcutâneo próximo do local da inoculação. Área de necrose de fibras musculares da camada média com hemorragia intramural. HE, obj.10x. No detalhe, rompimento do endotélio vascular; há hemorragia, infiltrado neutrofílico e necrose de fibras musculares. HE, obj.25x. (Ovino 5751, Bothropoides jararaca) moderada tumefação celular difusa, focos de necrose paracentral e/ou centro-lobular incipientes, caracterizados por cariopicnose em grupos de células, por vezes, associada à vacuolização citoplasmática de distribuição para-central, nessas áreas havia leve edema nos espaços Disse e leve dilatação dos sinusóides. Foram observados também infiltrados neutrofílicos e eosinofílicos nas áreas de necrose e indícios de atividade pró-coagulatória (microtrombos granulares) e corpúsculos de choque granulares.

Ao exame histopatológico do local da inoculação dos animais que receberam o veneno de Bothrops jararacussu (Ovinos 5752 e 5754) observaram-se edema com discreta hemorragia, necrose na porção superficial da derme, delimitada por linha de demarcação inflamatória, hemorragia e congestão de vênulas (Fig.9). Na derme profunda e no tecido celular subcutâneo havia acentuado edema com pequenas áreas de hemorragia, leucocitostase, dilatação de linfáticos, acentuada congestão e necrose da parede de vasos com infiltração de neutrófilos e presença de trombos em alguns vasos, além de acentuado edema e, por vezes, hemorragia ao redor de plexos nervosos. Na musculatura adjacente verificaram-se marcada necrose hialina de fibras musculares com infiltração neutrofílica, edema entre as fibras e entre grupos de fibras com derrame de fibrina. A necrose era mais evidente nas fibras próximas ao derrame fibrinoso (Fig.10). Nos linfonodos regionais, havia excesso de fluido drenado e infiltração por neutrófilos na medular. Na região contralateral observou-se necrose de coagulação individual de miócitos. Nos músculos esqueléticos distantes do local da inoculação, não havia qualquer outra alteração significativa.

Nos rins observaram-se necrose de coagulação em alguns túbulos do córtex, associada à infiltração neutrofílica e à tumefação e vacuolização de alguns túbulos. Havia

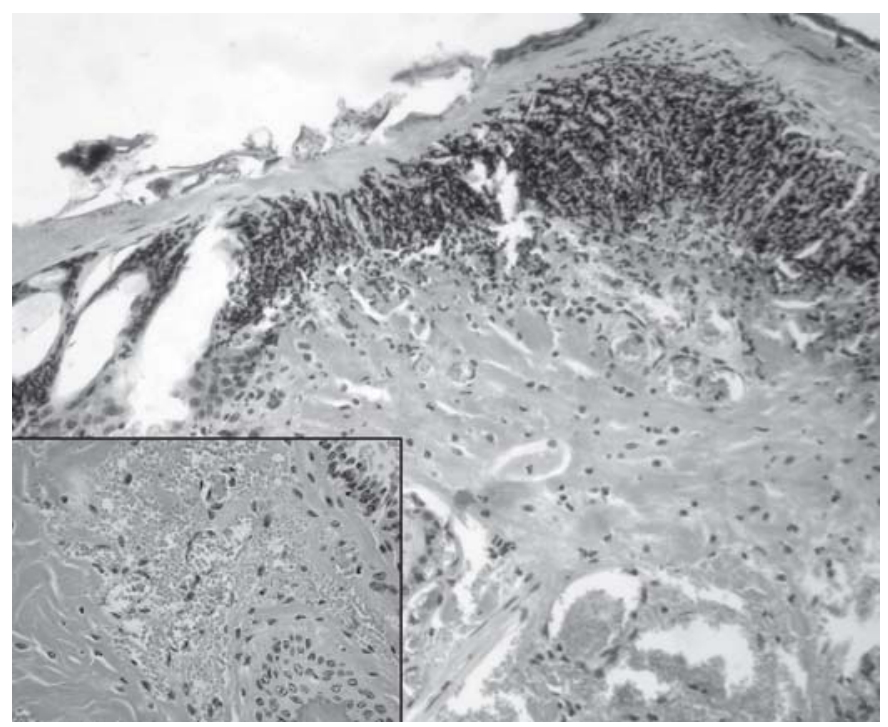

Fig.9. Pele no local da inoculação. Linha de demarcação (infiltrado neutrofílico) da área necrótica superficial (Obj.10x). No detaIhe, hemorragia na derme e ruptura de vênulas. HE, obj.25x. (Ovino 5752, Bothrops jararacussu) 


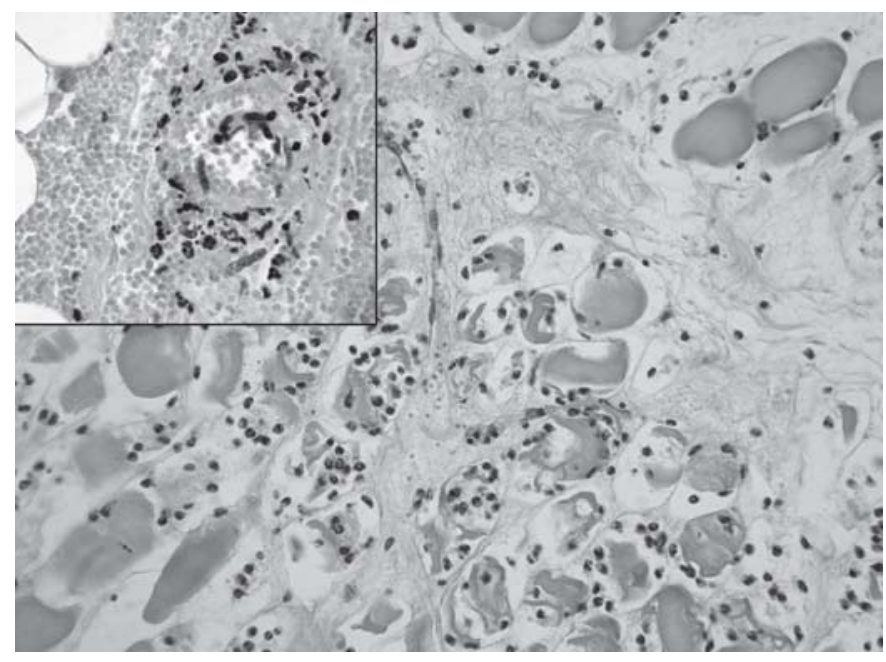

Fig.10. Fibras musculares necróticas, em parte já infiltradas por polimorfonucleares neutrófilos; note edema intersticial com derrame de fibrina ( $\mathrm{HE}$, obj.25x). No detalhe, necrose de arteríola, com infiltração inflamatória neutrofílica com hemorragia no tecido celular subcutâneo. HE, obj.25x. (Ovino 5752, Bothrops jararacussu)

também, dilatação de cápsulas de Bowmann com aumento do filtrado glomerular, presença de cilindros hialinos intratubulares e degeneração em gotas hialinas, além de formação incipiente de microtrombos em alguns glomérulos e capilares, leve congestão principalmente na junção córtico-medular e mineralização em túbulos da medular e junção córtico-medular. No fígado havia moderada congestão centro-lobular e peri-portal, leve degeneração gordurosa e infiltração mononuclear peri-portais e células tumefeitas, principalmente, na região central. Verificaram-se ainda moderado edema alveolar e ao redor de vasos e septos pulmonares, além de sinais de atividade pró-coagulatória.

Outros achados foram discreta hemorragia no córtex da adrenal, subendocárdica e miocárdica. Na bexiga foi observada leve congestão dos vasos da lâmina própria e de vasos da musculatura detrusora, que também apresentava tumefação e vacúolos em algumas fibras (região mais próxima à serosa). Verificou-se em linfonodos, edema nos seios medulares e em tecido adiposo ao redor do linfonodo e discreta congestão de vasos da cortical.

\section{DISCUSSÃO}

\section{Aspectos toxicológicos e metodologia}

Nos experimentos piloto, a inoculação via subcutânea foi feita na região do músculo masseter, na tentativa de reproduzir os achados observados por Tokarnia et al. (2008). Nos experimentos subsequentes, para evitar a compressão da região inoculada durante o decúbito, optamos por inocular o veneno à altura do terço médio do músculo semimembranoso; local e via de aplicação foram iguais às descritas por Araújo et al. (1963) e Caldas et al. (2008) em bovinos.

Neste estudo realizamos experimentos auto-direcionados, isto é, os resultados de um experimento direcionaram o subseqüente, com o intuito de diminuir o número de animais utilizados. Portanto, optamos inicialmente pela dose de $1,0 \mathrm{mg} / \mathrm{kg}$ para Bothropoides jararaca e $1,6 \mathrm{mg} / \mathrm{kg}$ para Bothrops jararacussu por via subcutânea, a mesma utilizada em bovinos por Araújo et al. (1963), por não haver descrição, na literatura, de doses letal e não-letal para ovinos. Com estas doses, os períodos de evolução foram muito curtos. Diminuímos então, a dose para 0,5 e 0,8mg/ $\mathrm{kg}$, respectivamente. Verificou-se, após a redução da dose que, para o veneno de $B$. jararaca, o animal apresentou sintomatologia clínica semelhante, mas não veio a óbito, recuperando-se completamente após 13 dias. O mesmo não ocorreu com o animal que recebeu metade da dose inicial de veneno da B. jararacussu, que apresentou sintomas clínicos e evolução para o óbito semelhante ao que ocorrera com o primeiro animal.

\section{Quadro clínico geral}

Como descrito por Araújo \& Belluomini (1960/62) e Tokarnia et al. (2008) em casos naturais e Caldas et al. (2008) em experimentos, houve o rápido aumento de volume local. É importante ressaltar que, na literatura em geral, esse aumento de volume é descrito ou interpretado como edema. Em ovinos, naturalmente envenenados por Bothrops jararaca (atualmente Bothropoides jararaca), trata-se de hemorragia e não edema (Tokarnia et al. 2008). Nos achados verificados em nossos experimentos com o veneno do ofídio de mesma espécie (Ovinos 5751 e 5753), verificamos que havia extensas áreas de hemorragia associadas a edema. Já nos animais inoculados com o veneno de $B$. jararacussu, a principal alteração local foi o acentuado edema associado à hemorragia (Ovinos $5752 \mathrm{e}$ 5754). Por outro lado, não se pode afirmar que o mesmo ocorra com relação a outros ofídios do antigo gênero Bothrops, nem a outras espécies envenenadas, uma vez que os venenos ofídicos, comprovadamente, podem ter efeitos variados em função da espécie animal em que são inoculados. Fato semelhante já foi observado em numerosos bovinos inoculados com o veneno de Crotalus durissus terrificus (Crotalus durissus atualmente classificada como Caudisona durissa), que não desenvolveram mioglobinúria, como ocorre em parte dos humanos envenenados pelo mesmo ofídio (Birgel et al. 1983, Graça et al. 2008). Um animal (Ovino 5751) apresentou dificuldade em ingerir água, provavelmente, pelo grande aumento de volume na face $e$ região submandibular. Os animais que receberam o veneno no MPD apresentaram sinais de dor como claudicação e arrastar de pinça, mesmo com a administração de morfina epidural. O Ovino 5753 apresentou sonolência, provavelmente associada ao efeito da morfina. Sinais clínicos como dor e grande aumento de volume no local da inoculação do veneno são descritos tanto em casos naturais (Grunet \& Grunet 1969, Méndez \& Riet-Correa 1995, Menezes 1995/96, Who 2007), quanto experimentais (Araújo \& Belluomini 1960/62, Novaes et al. 1986, Soerensen et al. 1995, Caldas et al. 2008) por serpentes do antigo gênero Bothrops, independente da espécie acometida. $\mathrm{O}$ aumento da fre- 
qüência cardíaca, observado em todos os animais, pode ter sido determinado pela hipovolemia (perda de sangue ou plasma) ou mesmo pela dor. Observou-se, nos Ovinos 5751 e 5754, dispnéia mista, caracterizada por aumento da intensidade dos movimentos inspiratórios e expiratórios, que ocorria na fase final do envenenamento, possivelmente, devido ao quadro de choque hipovolêmico e edema pulmonar agudo, respectivamente. A temperatura manteve-se dentro dos parâmetros fisiológicos em todos os animais, exceto no Ovino 5751, que teve diminuição da temperatura nos momentos finais do curso clínico. Aumento da frequência cardíaca, mucosas hipocoradas e hipotermia também podem ocorrer no choque hipovolêmico. É provável que o acentuado quadro hemorrágico tenha induzido ao choque hipovolêmico e tenha sido determinante para a morte do animal que recebeu o veneno de $B$. jararaca. Os animais que receberam o veneno de $B$. jararacussu vieram a óbito com um quadro de edema pulmonar agudo. Uma importante causa do edema pulmonar é a coagulação intravascular disseminada (CID), que pode ter origem após ativação dos fatores de coagulação ou pela disseminada agressão às células endoteliais (Cotran et al. 2000).

Em bovinos (Grunert 1967, Grunet \& Grunet 1969, Méndez \& Riet-Correa 2007) e equinos (Raposo et al. 2000/ 01) naturalmente envenenados e em bovinos (Caldas et al. 2008) e ovinos (Araújo \& Belluomini 1960/62) experimentalmente inoculados, foram verificados hematoquesia, achado observado em um animal do nosso estudo (Ovino 5751).

As colheitas de sangue (punções) realizadas em T24 e T96, para o animal que sobreviveu, não induziram a formação de grandes hematomas, determinados pelo efeito anticoagulante do veneno, como descrito em bovinos (Caldas et al. 2008) e caninos (Santos et al. 2003) experimentalmente inoculados com o veneno da Bothrops alternatus (atualmente Rhinocerophis alternatus) e em ovinos (Aires et al. 2008) naturalmente envenenados por um exemplar deste gênero.

Ao contrário do descrito por Araújo \& Belluomini (1960/ 62 ), os animais que receberam o veneno de $B$. jararacus$s u$, tiveram evolução ao óbito mais rápida do que o que recebeu o veneno de $B$. jararaca. Também não foram observadas alterações correspondentes a ação crotoxin-like do veneno de $B$. jararacussu, como descrito por Queiroz (1981 apud Pai \& Santo Neto 1999), Oshima-Franco et al. (2001) e Queiroz et al. (2002).

\section{Resultados laboratoriais}

$\mathrm{Na}$ avaliação do eritrograma verificou-se, em dois animais, moderada anemia normocítica normocrômica, alteração que também foi observada em bovinos por Oliveira et al. (2004) e Caldas et al. (2008). O quadro hemorrágico causou acentuada diminuição do hematócrito e da concentração de hemoglobina (Ovinos 5751 e 5753). O aumento do hematócrito, observado nos Ovinos 5752 e 5754, ocorreu devido à hemoconcentração, por perda de líquido no parênquima pulmonar e nos tecidos no local da inocula- ção e adjacências. O leucograma apresentou discreta leucocitose caracterizada por neutrofilia, monocitose, linfopenia e eosinopenia, que pode estar associada ao estresse. Por outro lado, estas alterações de estresse são mais intensas no envenenamento por Crotalus durissus terrificus (Graça et al. 2008). Verificou-se ainda um discreto desvio de neutrófilos à esquerda (aumento de bastões) em dois animais, provavelmente associado ao processo inflamatório agudo no local da inoculação.

Houve acentuada diminuição de plaquetas em todos os animais e, em dois animais, as proteínas plasmáticas totais apresentaram-se moderadamente diminuídas (Ovinos 5751 e 5753). Nos dois animais que receberam o veneno da $B$. jararacussu, as proteínas plasmáticas totais estavam aumentadas, provavelmente pela discreta hemólise do plasma. A principal causa da trombocitopenia observada no envenenamento botrópico parece ser a ativação das plaquetas circulantes pela trombina. A botrocetina e a PA-BJ contribuem para a indução da trombocitopenia, assim como outros componentes com atividades próagregante plaquetária presentes no veneno de Bothrops jararaca (Santoro 2002) e BJcul e trombocetina presentes no veneno da $B$. jararacussu. Este quadro também foi evidenciado em humanos (Barraviera 1999) e em bovinos (Caldas et al. 2008). A moderada diminuição das proteínas plasmáticas totais foi, provavelmente, decorrente da hemorragia ou perda de plasma no edema. Os níveis de fibrinogênio estavam acentuadamente diminuídos, como no envenenamento em humanos (Barraviera 1999) e em cães (Pérez et al. 1997). Este fenômeno pode ser explicado pela ação de componentes presentes nos dois venenos utilizados no presente estudo (Jararafibrase I e II, KN-BJ 1 e 2, TL-BJ 1, 2 e 3; Jararacussin I), que consomem parte do fibrinogênio circulante.

Todos os animais apresentaram acentuado aumento nos níveis de creatinaquinase (CK) e dehidrogenase lática (DHL). Os Ovinos 5751, 5753 e 5752 apresentaram discreto a leve aumento dos níveis de uréia, e os Ovinos 5752 e 5754 tinham acentuado aumento nos valores de creatinina.

Em humanos envenenados por serpentes do antigo gênero Bothrops (França \& Málaque 2003) e em camundongos, ratos (Melo \& Suares-Kurtz 1987, Santos et al. 1992, Calil-Elias et al. 2002, Sifuentes et al. 2008) e bovinos inoculados experimentalmente (Caldas et al. 2008), os níveis de CK também estavam aumentados. Em humanos, França \& Málaque (2003) verificaram que CK e DHL também encontravam-se aumentadas em pacientes com processo inflamatório no local da picada. Os níveis séricos de uréia sofreram aumento, possivelmente, devido ao estresse. Contudo, Alencar \& Servaes (1994) averiguaram que o aumento de CK também pode ser decorrente de traumatismo muscular e quadro de choque. Em casos de choque, a hipotensão diminui o débito cardíaco e aumenta a produção de lactato, que por sua vez, termina por lesar as fibras musculares; quanto maior o tempo em que o indivíduo fica em choque, maiores serão as lesões tissulares e os níveis de CK (Cecil et al. 2005). O acentu- 
ado aumento dos níveis séricos de CK também podem ocorrer no decúbito prolongado (Souza Júnior et al. 2007) e na síndrome da vaca caída (Radostits et al. 2000).

Verificou-se acentuado aumento no tempo de sangramento em todos os animais. Esta alteração foi observada tanto em humanos (Ribeiro \& Jorge 1997), quanto em bovinos (Menezes 1995/96, Caldas et al. 2008) e caninos (Takahira 1996). TAP e TTPA estavam acentuadamente aumentados. O aumento do TAP pode estar associado à ativação ou inibição de alguns dos fatores de coagulação como fator I, II, V, VII ou X (vias extrínseca e comum da coagulação). Já o aumento do TTPA, provavelmente, ocorreu pela ativação ou inibição de alguns dos fatores como VIII, IX, X, XI, XII, II ou I (Cotran et al. 2000), causada pela protease trombocitina (vias intrínseca e comum). $O$ aumento do TAP e do TTPA indica que as vias intrínseca e extrínseca foram comprometidas e, conseqüentemente, a via comum.

\section{Achados de necropsia}

Verificamos alterações macroscópicas significativas que, quando associadas ao histórico, permitem fornecer subsídios para diagnóstico de provável envenenamento botrópico. Quando há quadro hemorrágico, contudo aparentemente, não se pode estabelecer qual serpente é a causa do acidente (por exemplo, Bothropoides jararaca ou Rhinocerophis alternatus), a menos que haja comprovação de que o animal foi picado por aquela espécie encontrada no local. Por outro lado, os dois animais que foram inoculados com o veneno da Bothrops jararacussu vieram a óbito com edema pulmonar agudo, dado que talvez seja importante para o estabelecimento do diagnóstico diferencial.

Todos os animais apresentaram grande aumento de volume de natureza diferente, independente do tipo e da dose do veneno ou do local da inoculação. Para os animais que receberam o veneno da $B$. jararaca, este aumento de volume era de natureza sobretudo hemorrágica com discreto edema, ao contrário dos que receberam o veneno da $B$. jararacussu, que caracterizava-se mais por "edema hemorrágico". Tanto a hemorragia, quanto o "edema hemorrágico" se estendiam pelo tecido subcutâneo e musculatura subjacente. $O$ animal que recebeu o veneno da $B$. jararaca, apresentou extensa área, predominantemente, hemorrágica, que se restringia ao tecido subcutâneo e se estendia desde o ponto de inoculação até a região esternal. As hemorragias intramusculares ocorreram em áreas próximas ao ponto de inoculação, provavelmente, pela distribuição do veneno ser maior no tecido subcutâneo. De fato, achados semelhantes, mas não iguais, foram descritos nos experimentos realizados em bovinos inoculados com o veneno de B. alternatus, por Caldas et al. (2008). Foi observado, nos animais que receberam o veneno da $B$. jararacussu, que o edema se estendia por todo tecido subcutâneo no ponto da inoculação e tecidos adjacentes, inclusive na musculatura. O termo hematoma não é utilizado na maioria dos trabalhos; os autores empregam a palavra "edema" para definir ou descrever o aumento de volume local, não só em bovinos, mas também em humanos e em outros animais (Araújo et al. 1963, Novaes et al. 1986, Bicudo 1994, Menezes 1995/96, Pérez et al. 1997, Ribeiro \& Jorge 1997, Barraviera 1999, Teibler et al. 1999, Méndez \& Riet-Correa 2007). Ver diagnóstico diferencial mais a frente.

As desordens hemorrágicas podem ser causadas provavelmente, por degradação dos fatores de coagulação (X, II, VIII) (Nahas et al. 1979, Souza et al. 2000, Cominetti et al. 2003) e comprometimento plaquetário (trombocitopenia). Os linfonodos regionais, independentemente do local da inoculação, encontravam-se de aspecto hemorrágico/edemaciado, ao que tudo indica por drenarem sangue/ edema das áreas adjacentes à inoculação.

\section{Achados histopatológicos}

A aplicação dos venenos de $B$. jararaca e $B$. jararacus$s u$, por via subcutânea, produziram leves alterações regressivas no fígado, e necrose tubular nos rins. Essas alterações não foram consideradas significativas e nem relacionadas diretamente ao efeito do veneno botrópico. Lesões semelhantes têm sido observadas em quadros de choque (Jones et al. 1996). O achado de corpúsculos de choque em veias hepáticas sugere que essa hipótese está correta.

A necrose coagulativa de fibras musculares nas adjacências do local de inoculação pode estar associada à hipóxia celular ocasionada pela intensa hemorragia/edema, que impede a adequada oxigenação dos tecidos nessa área, bem como pela compressão exercida pelo aumento de volume, como postulam Pai \& Santo Neto (1999) ou, ainda, ser decorrente do efeito direto dos fatores miotóxicos do veneno.

A lesão vascular encontrada após a inoculação dos venenos também foi descrita em camundongos inoculados com o veneno da $B$. jararaca, $B$. jararacussu (Pérez et al. 2007) e B. alternatus (Queiróz \& Petta 1984).

\section{Diagnóstico diferencial}

No que se refere aos aspectos epidemiológicos, é importante o conhecimento da distribuição geográfica e o habitat das serpentes. Segundo Tokarnia \& Peixoto (2006) há uma superestimação de casos de acidentes ofídicos como causa de óbito de bovinos. Por exemplo, na Região Norte, muitas pessoas associam o acidente ofídico às mortes súbitas em bovinos, porém, nessa região, a maior parte das mortes em bovinos está relacionada à ingestão de plantas tóxicas, principalmente, das que causam morte súbita.

Os quadros clínicos do envenenamento por Bothropoides jararaca e por Bothrops jararacussu são de evolução rápida, caracterizados basicamente, por grande aumento de volume no local da inoculação. É importante ressaltar que, na literatura, há confusão entre os quadros clínicopatológicos observados em animais envenenados por serpentes do antigo gênero Bothrops, com os induzidos por cascavéis norte-americanas (Habermehl 1977). 
As alterações macroscópicas aqui descritas, quando associadas ao histórico, fornecem subsídios para diagnosticar os envenenamentos por $B$. jararaca e $B$. jararacussu em ovinos. É importante levar-se em conta, porém, que pode haver diferenças substanciais na natureza (constituição) do aumento de volume verificado no local e adjacências da inoculação ou da picada. Nesse caso de inoculação experimental por veneno de $B$. jararaca verificou-se hemorragia local predominante, com edema em menor proporção. Contudo, Tokarnia et al. (2008) observaram um qua-dro essencialmente hemorrágico em um ovino picado por $B$. jararaca, em tudo semelhante aos achados macroscópicos descritos no envenenamento experimental por $B$. alternatus (Caldas et al. 2008). Já no caso da inoculação experimental por $B$. jararacussu, predominava edema associado à hemorragia no local da inoculação e adjacências.

Portanto, outras condições hemorrágicas como intoxicação por warfarina, eventualmente devem ser consideradas no diagnóstico diferencial não só de envenenamento por $B$. alternatus, como por B. jararaca. Por outro lado, aumentos de volume localizados no tecido celular subcutâneo, como se observa no edema maligno e na face de ovinos como marcada fotossensibilização devem ser levados em conta no estabelecimento do diagnóstico diferencial dos envenenamentos por serpentes do antigo gênero Bothrops, de uma forma geral. O exame acurado do que constitui o aumento de volume, talvez pudesse dar alguma indicação da espécie de ofídio do antigo gênero Bothrops eventualmente implicada no acidente, todavia só através de um maior número de experimentos, poderia se comprovar ou refutar essa hipótese, uma vez que diversos fatores podem influenciar na constituição e toxidez do veneno de serpentes, entre os quais idade, sexo, predação recente, etc. Os dois animais inoculados com o veneno de $B$. jararacussu morreram em função do acentuado edema pulmonar agudo, dado que talvez possa ser utilizado no diagnóstico diferencial.

Agradecimentos.- Ao Dr. Aníbal Rafael Melgarejo e a Luis Eduardo Ribeiro da Cunha, Instituto Vital Brazil, Niterói, RJ, por terem fornecido os venenos ofídicos.

\section{REFERÊNCIAS}

Aires R.A., Marin J.B., Cecim M.S. \& Leal M.L.R. 2008. Acidente ofídico em ovinos da região central do Rio Grande do Sul. Anais 35은 Conbravet, Gramado, RS. (Resumo)

Alencar R.A. \& Servaes C.R. 1994. Guia para o Diagnóstico em Medicina Veterinária. Nobel, São Paulo. 205p.

Araújo P. \& Belluomini H.E. 1960/62. Toxicidade de venenos ofídicos I: sensibilidade específica de animais domésticos e de laboratório. Mem. Inst. Butantã 30:143-156.

Araújo P., Rosenfeld G. \& Belluomini H.E. 1963. Toxicidade de venenos ofídicos II: doses mortais para bovinos. Arqs Inst. Biológico, São Paulo, 30:43-48.

Barraviera B. 1999. Ofídios: estudos clínicos dos acidentes. EPUB, Petrópolis. 411p.

Bicudo P.L. 1994. Acidentes ofídicos em Medicina Veterinária, p.375387. In: Barraviera B. (Ed.), Venenos Animais: uma visão integrada. EPUB, Rio de Janeiro.
Birgel E.H., Belluomini H.E. \& Leinz E.E. 1983. Auswertung der Urinbefunde bei Rindern mit experimenteller Crotalus-Vergiftung. Zentralbl. Veterinärmed. 30:283-289.

Caldas S.A., Tokarnia C.H., França T.N., Brito M.F., Graça F.A.S., Coelho C.D. \& Peixoto P.V. 2008. Aspectos clínico-patológicos e laboratoriais do envenenamento experimental por Bothrops alternatus em bovinos. Pesq. Vet. Bras. 28:303-312.

Calil-Elias S., Thattassery E., Martinez A.M.B. \& Melo P.A. 2002. Effect of perimuscular injection of Bothrops jararacussu venom on plasma creatine kinase levels in mice: influence of dose and volume. Braz. J. Med. Biol. Res. 35:1233-1235.

Cecil R.L., Goldman L. \& Ausiello D. 2005. Tratado de Medicina Interna. $22^{a}$ ed. Elsevier, Rio de Janeiro. 2776p.

Cominetti M.R., Ribeiro J.U., Fox J.W. \& Selistre-de-Araujo H.S. 2003. BAG, a new dimeric metalloproteinase/disintegrin from the Bothrops alternatus snake venom that interacts with $\alpha 2 \beta 1$ integrin. Arch. Biochem. Biophys. 416:171-179.

Cotran R.S., Kumar V. \& Collins T. 2000. Robins' Patologia Estrutural e Funcional. 6를 ed. Guanabara Koogan, Rio de Janeiro. 1250p.

Fonteque J.H., Barros Filho I.R. \& Sakate M. 2001. Acidentes botrópicos de interesse em animais domésticos. Revta Educ. Cont. CRMV/SP 4:102-111.

França F.O.S. \& Málaque C.M.S. 2003. Acidente botrópico, p.72-86. In: Cardoso J.L.C., França F.O.S., Wen F.H., Málaque C.M.S. \& Haddad Jr V. (Eds), Animais Peçonhentos: biologia, clínica e terapêutica dos acidentes. Sarvier, São Paulo.

Garcia-Navarro C.E.K. \& Pachaly J.R. 1994. Manual de Hematologia Veterinária. Varela, São Paulo. 169p.

Graça F.A.S., Peixoto P.V., Coelho C.D., Caldas S.A., Tokarnia C.H. 2008. Aspectos clínico-patológicos e laboratoriais do envenenamento crotálico experimental em bovinos. Pesq. Vet. Bras. 28(6):261-270.

Grunert E. 1967. Beobachtungen über Schlangenbissverletzungen bei grossen Haustieren in Süd-Brasilien. Dtsch. Tierärztl. Wochenschr. 74(20):531-532.

Grunert E. \& Grunert D. 1969. Observaciones de lesiones por mordedura de serpiente Bothrops em los bóvidos y caballos em Rio Grande do Sul/Brasil. NMV 3:213-227.

Habermehl G. 1977. Gift-Tiere und ihre Waffen. 2.Aufl. Springer Verlag, Berlin.

Jones T.C., Hunt R.D. \& King N.W. 1996. Veterinary Pathology. $6^{\text {th }}$ ed. Lippincott Williams and Wilkins, Philadelphia. 1392p.

Melgarejo R.A. 2010. Comunicação pessoal (Instituto Vital Brazil, Niterói, $\mathrm{RJ})$.

Melo P.A. \& Suarez-Krutz G. 1987. Interaction of Bothrops venoms and antivenin on release of creatine kinase from skeletal muscle. Braz. J. Med. Biol. Res. 20(6):821-824.

Méndez M.C. \& Riet-Correa F. 1995. Snakebite in sheep. Vet. Hum. Toxicol. 37(1):62-63.

Méndez M.D.C. \& Riet-Correa F. 2007. Doenças tóxicas: envenamento botrópico, p.31-38. In: Riet-Correa F., Schild A.C., Lemos R. \& Borges J.R.J. (Eds), Doenças em Ruminantes e Equinos. Vol.2. 3를 ed. Varela Editora, São Paulo.

Menezes R.V. 1995/96. Ofidismo em bovinos. Arq. EMV/UFBA 18(1): 24-230.

Muir W.W. \& Hubbell J.A.E. 1995. Handbook of Veterinary Anesthesia. $2^{\text {nd }}$ ed. Mosby, St Louis. 510p.

Nahas L., Kamiguti A.S. \& Barros A.R. 1979. Thrombin-like and factor X-activator components of Bothrops snake venoms. J. Thromb. Haemost. 41:314-328.

Novaes A.P., Lucas S., Abe A.S., Fernandes W., Puorto G. \& Almeida I.L. 1986. Envenenamento botrópico em bovinos: tratamento opcional. Circular Técnica no.3, Embrapa, p.1-15.

Oliveira N.J.F., Melo M.M., Ribeiro E.L., Lago L.A. \& Lucia M. 2004. 
Achados histopatológicos em bovinos experimentalmente envenenados com veneno de Bothrops alternatus. XXXI Conbravet, São Luiz, MA. (Resumo)

Oshima-Franco Y., Leite G.B., Silva G.H., Cardoso D.F., Hyslop S., Giglio J.R., Cruz-Höfling M.A. \& Rodrigues-Simion L. 2001. Neutralization of the pharmacological effects of bothropstoxin-I from Bothrops jararacussu (jararacuçu) venom by crotoxin antiserum and heparin. Toxicon. 39(10):1477-1485.

Pai V.D. \& Santo Neto H. 1999. Ação dos venenos ofídicos sobre os tecidos animais, p.97-105. In: Barraviera B. (Ed.), Venenos: aspectos clínicos e terapêuticos dos acidentes por animais peçonhentos. EPUB, Rio de Janeiro.

Pérez O.A., Koscinczuk P., Flinta S.M., Maidana H.R. \& Negrette M.S. 1997. Bothrops alternatus envenoming in young dogs. J. Venom. Anim. Toxins 3(1):43-47.

Queiróz L.S. 1981. Effects of neurotoxins on muscle and nerve in the mouse: Morphological and physiological studies. Am. J. Pathol. 76:401414. (Apud Pai \& Santo Neto 1999)

Queiróz L.S. \& Petta C.A. 1984. Histopathological changes caused by venom of urutu snake (Bothrops alternatus) in mouse skeletal muscle. Revta Inst. Med. Tropical 26(5):247-253.

Queiróz L.S., Marques M.J. \& Santo Neto H. 2002. Acute local nerve lesions induced by Bothrops jararacussu snake venom. Toxicon 40(10):1483-1486.

Radostits E.M., Arundel J.H. \& Gay C.C. 2000. Veterinary Medicine. $9^{\text {th }}$ ed. W.B. Saunders, London. 1877p.

Raposo J.B., Méndez M.C., Baialardi M.E.G. \& Raffi M.B. 2000/01. Acidente ofídico em eqüino no Rio Grande do Sul: relato de caso. Revista FZVA 7/8(1):5-8.

Ribeiro L.A. \& Jorge M.T. 1997. Acidente por serpentes do gênero Bothrops: série de 3139 casos. Revta Soc. Bras. Med. Tropical 30(6):475-480.

Saliba A.M., Belluomini H.E. \& Leinz F.F. 1983. Experimentelle CrotalusVergiftung bei Rindern: Anatomisch-pathologische Studie. Dtsch. Tierärztl. Wochenschr. 90:513-517.

Santoro M.L. 2002. Contribuição à investigação das alterações hemostáticas induzidas pelo veneno da serpente Bothrops jararaca em coelhos: estudo das glicoproteínas da membrana, função, secreção e sobrevivência plaquetárias. Tese de Doutorado em Ciências, Instituto de Biociências, USP, São Paulo, SP. 194p.

Santos M.C., Gonçalves L.R.C., Fortes-Dias C.L., Cury Y., Gutiérrez
J.M. \& Furtado M.F.D. 1992. A eficácia do antiveneno botrópicocrotálico na neutralização das principais atividades do veneno de $B$. jararacussu. Revta Inst. Med. Tropical 34(2):77-83.

Santos M.M.B., Melo M.M., Jacome D.O., Ferreira K.M. \& Sabaini R.M. 2003. Hemograma de cães envenenados experimentalmente com Bothrops alternatus após diferentes tratamentos. Revta Bras. Saúde Prod. Anim. 4(1):1-11.

Sifuentes D.N., El-Kik C.Z., Tomaz M.A., Strauch M.A., Ricardo H.D., Calil-Elias S.C., Arruda E.Z., Schwartz E.F. \& Melo P.A. 2008. Ability of sumarin to antagonize the cardiotoxic and some enzymatic activities of Bothrops jararacussu venom. Toxicon 51(1):28-36.

Soerensen B., Barros A.R., Zezza Neto L., Oliveira A.M., Santos R.V., Messias C.V., Silva A.R.C., Capossoli E.A., Cavalcante N.B.C., Vellucci S.C.C., Repetti E., Santos P.C.G., Pacchini C.E. \& Alves Júnior M. 1995. Aspecto clínico e laboratorial do envenenamento botrópico e crotálico em bovinos. Unimar Ciências 4(2):28-33.

Souza D.H.F., lemma M.R.C., Ferreira L.L., Faria J.P., Oliva M.L.V., Zingali R.B., Niewiarowski S. \& Selistre-de-Araujo H.S. 2000. The disintegrin-like domain of the snake venom metalloprotease alternagin inhibits $\alpha 2 \beta 1$ integrin-mediated cell adhesion. Arch. Biochem. Biophys. 384(2):341-350.

Souza Júnior A.A., Aragão A.P., Rousso Filho R., Caldas S.A., Souza A.M. \& Graça F.A.S. 2007. Análise bioquímica de bovinos submetidos ao decúbito experimental. Revta Univ. Rural, Sér. Ciênc. Vida 27:580-582.

Takahira R. 1996. Alterações hemáticas e bioquímicas de cães no envenenamento experimental por Bothrops jararaca (Wiedi, 1824) e Bothrops newiedii (Wangler, 1824). Dissertação de Mestrado em Medicina Veterinária, Universidade Estadual Paulista, Botucatu, SP. (Apud Fonteque et al. 2001)

Teibler P., Pérez O.A., Maruñaque S., Ruiz R., Koscinczuk P., Sánchez Negrette M. \& Mussart de Coppo N. 1999. Lesiones locales y sistemicas inducidas por veneno de Bothrops alternatus (víbora de La cruz) de Argentina. Acta Toxicol. Argent. 7(1):7-10.

Tokarnia C.H. \& Peixoto P.V. 2006. Importância dos acidentes ofídicos como causa de mortes em bovinos no Brasil. Pesq. Vet. Bras. 26(2):55-68.

Tokarnia C.H., Brito M.F., Malafaia P. \& Peixoto P.V. 2008. Acidente ofídico em ovinos causado por Bothrops jararaca. Pesq. Vet. Bras. 28(12):643-648.

WHO 2007. Rabies and envenomings: A neglected public health issue. World Health Organization, Geneva. 38p. 